\title{
Application Research on Information System of Multimedia Catering Management Based on Relational Database
}

\author{
Lin $\mathrm{Xie}^{*}$
}

Guizhou Career Technical College, Guizhou Radio \& TV University, Guizhou, China

\begin{abstract}
Along with the rapid development of computer application technology in current society, information management is being applied to various industries. In this paper, through research on relational database, the author of this paper is going to create a modern efficient management system to change the catering enterprises' old management model that consumes labor and material resource. Through demand analysis, this paper will give design and standardization of business flow chart, data flow chart and E-R diagram to further develop database logical design and physical design, and create an efficient information system of multimedia catering management. While strengthening the management of enterprises, this will more satisfy the demand of the modern society on catering service industry.
\end{abstract}

Keywords: Catering management, E-R diagram, the relational database.

\section{INTRODUCTION}

With the development of computer information technology, the information tidal wave swept the world. In each industry, there is expectation of using the latest technology to drive the industry to a more rapid and beneficial development direction. Informatization's influence on the enterprises mainly reflects in two aspects: one is application management of computers within the enterprises and their derivatives; the other one is applying network to push their products to more users.

Food is always the paramount necessity of the people. In the modern society "food" is still pushed to a higher degree. Eating in the modern society pays attention to scientific and reasonable, as well as efficient enjoyment. The eating places that people look forward to shall not be just with good food as before, but are required to be efficient, environmental, comfortable and smart. With the rapid development of modern technology, combining modern technology and catering management is more and more popular around the people. In the contrary, tradition catering management not only needs a large amount of labor and material resource, while with low efficiency. This kind of management mode is against rapid development of catering enterprises and restricts large-scale development of catering enterprises and promotion of the whole catering industry's service level.

Following the constant improvement of China's economic development degree, increasing income of people, growing demand of catering consumption and increasing turnover of catering industry, China's catering industry is facing a broad market.

However, since small and medium-sized enterprises hold a large proportion in China's catering industry and there is no fixed mode of business management, information system of multimedia catering management is urgently required to be popularized.

\subsection{Writing Intention}

Applying database that is an information management technical application into catering management is the development trend of modern catering industry. It will increase soft power of domestic catering brands while competing with foreign catering brands. Using database information management technique, some advantages of it cannot be accomplished by labor management. For example, it can quickly deliver the menu to the kitchen, fully utilize cooks' time and make the checkout counter settle quickly. Its feedback evaluation system is beneficial for timely mastering the shop's business status and adjusting plan, while with good security, reliability, large storage, long service life and low cost, etc. Building database of catering management information can greatly improve efficiency of catering management, and is an important condition for enterprises' scientific and standard management, and integration with the world [1].

\subsection{Definition of the Software}

The software that involve in development of this database are mainly as follows:

Microsoft office visio 2003

Sybase powerdesigner 15.1

Microsoft office word 2003

Microsoft SQL Sever 2000

\subsection{Development Environment}

Operating system: Microsoft Windows 7

Hardware structure: Genuine Intel(R) CPUi3@ $2.0 \mathrm{GHz}$ $2.0 \mathrm{GHz}$ 


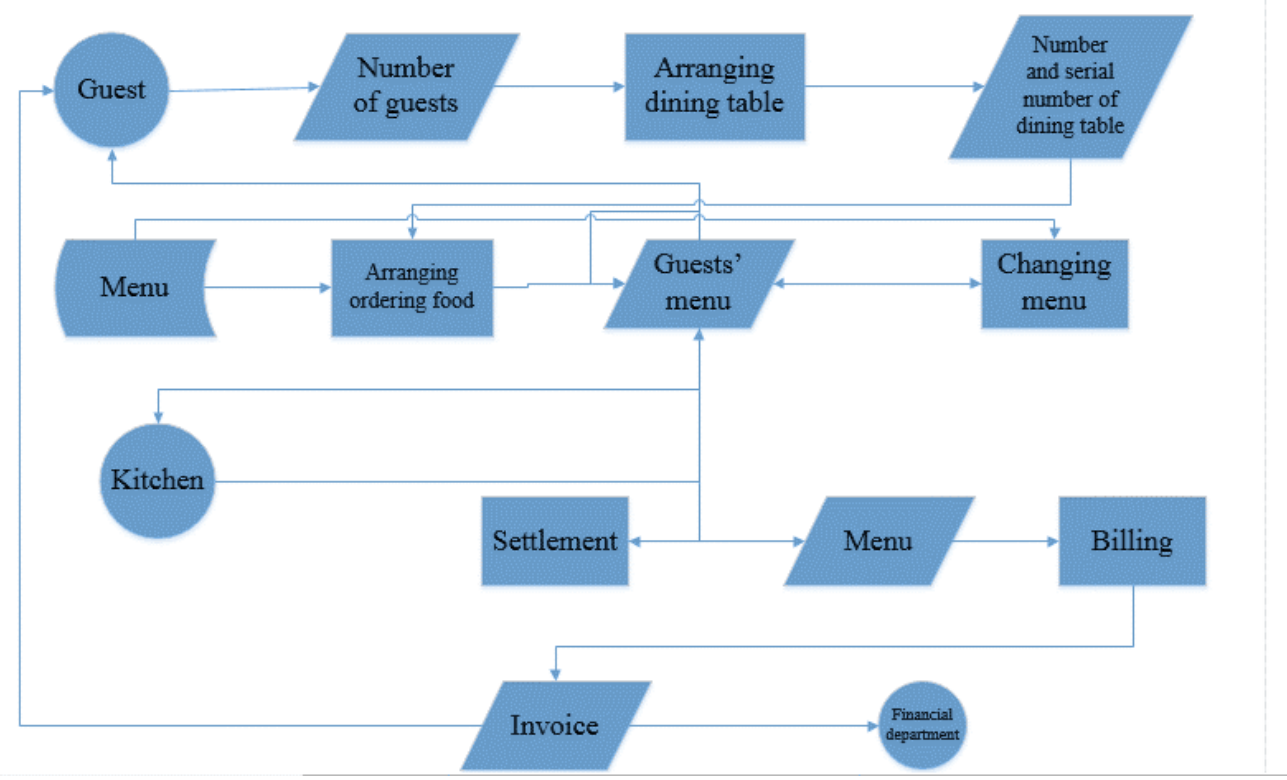

Fig. (1). Flow chart of business of catering management system.

\subsection{GB memory}

\section{DEMAND ANALYSIS}

\subsection{Problem Statement}

In catering industry, after the guests come in, table number shall be firstly confirmed according to the number and willing of the guests; then according to the actual situation serving the guests to order; after taking an order, sending the menu to the kitchen, where will arrange professionals to prepare food; in addition, the menu shall also be sent to the checkout counter to complete settlement quickly; during guests' meal, if they want to order more or return, they can change in the menu, while the kitchen timely confirming the menu and the checkout counter changing the menu; at last, settling guests' menu, generating a bill and sending the invoice to the guest. In this system, each section has own authority and management way.

Users' authorities are as follows:

Waiter: inputting guests' menu information to the system, timely sending the menu to the kitchen and checkout counter, as well as changing the menu to resend the changed content to the kitchen and checkout counter.

Kitchen: receiving the menu information directly and timely update the menu, and feeing unchangeable content to waiter.

Cashier: calculating the consumption amount of guests, generating bills, collecting money and generating invoices.

Financial staff: recording in account according to the invoices and reviewing financial statements.

The specific flow is presented in Fig. (1).

\subsection{Function Description}

Information flows directly among guests, kitchen, financial department and catering management system. The information input and output from different objects is different. The details are as Fig. (2).

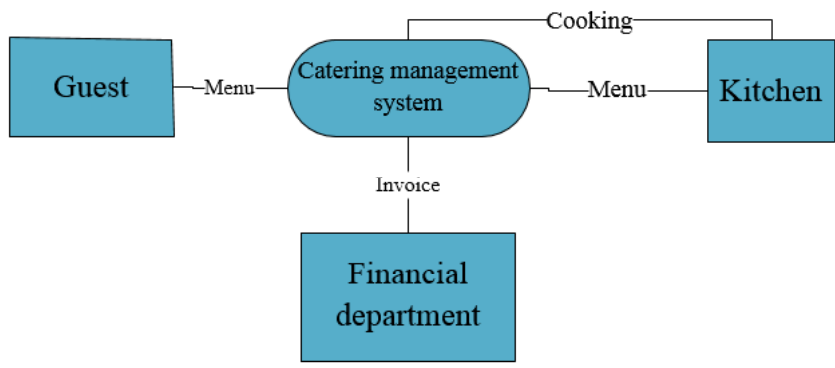

Fig. (2). Flow chart of first-class data of catering management system.

Subdividing information flow: after guests order food, there is need to provide menu for the, and timely provide the change one of menu after changing. At last, the settled invoice shall be delivered to guests. After checkout, the invoice shall be delivered to guests and financial departments separately. This is shown as Fig. (3).

Subdividing data of each item more finely: when arranging dining table, there shall be information status and serial number of table; in the menu, there must be information of dish style and amount; unit price and consumption amount must be present in billing information; subdivide these process once again, as Fig. (4).

\subsection{ER Model Diagram of Catering Management System}

In accordance with the content of function description, the primary E-R diagram is designed, with the following entity and links:

\subsubsection{Entities}

Information of guests' menu (serial number of dining table, serial number of guests, number, names and respective price of dishes, consumption amount and details of dishes).

Information of guests' dining table (number of guests, consumption time, and serial number, position, status and type of dining table) 


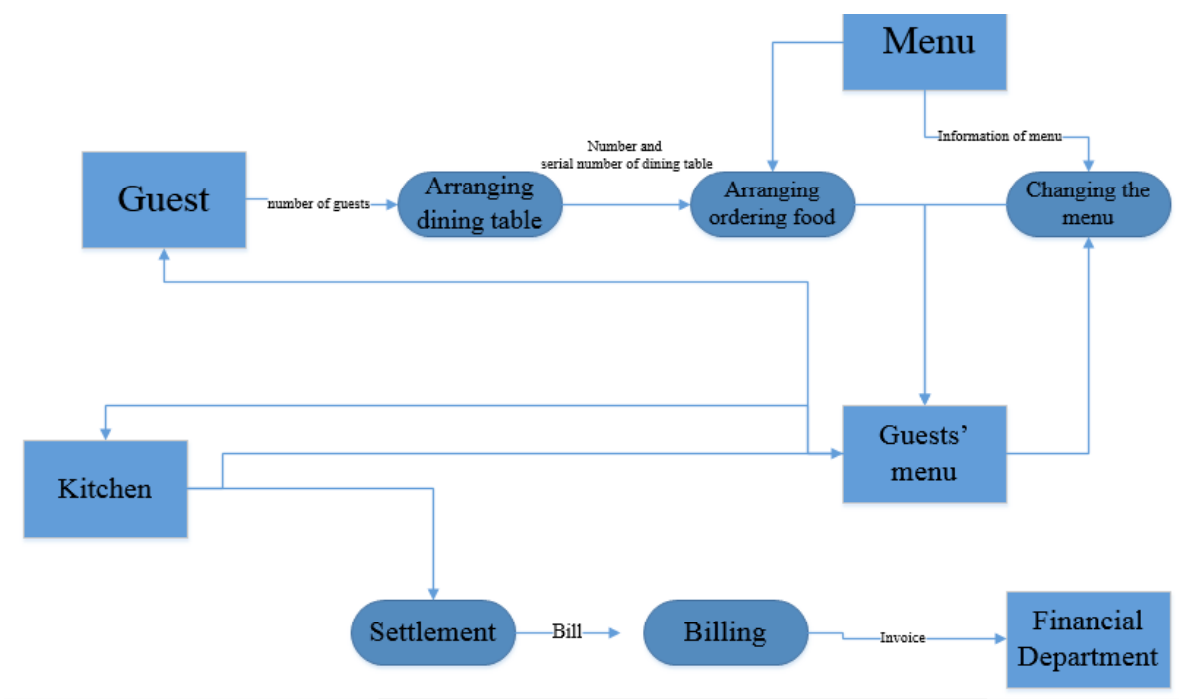

Fig. (3). Flow chart of secondary data of catering management system.

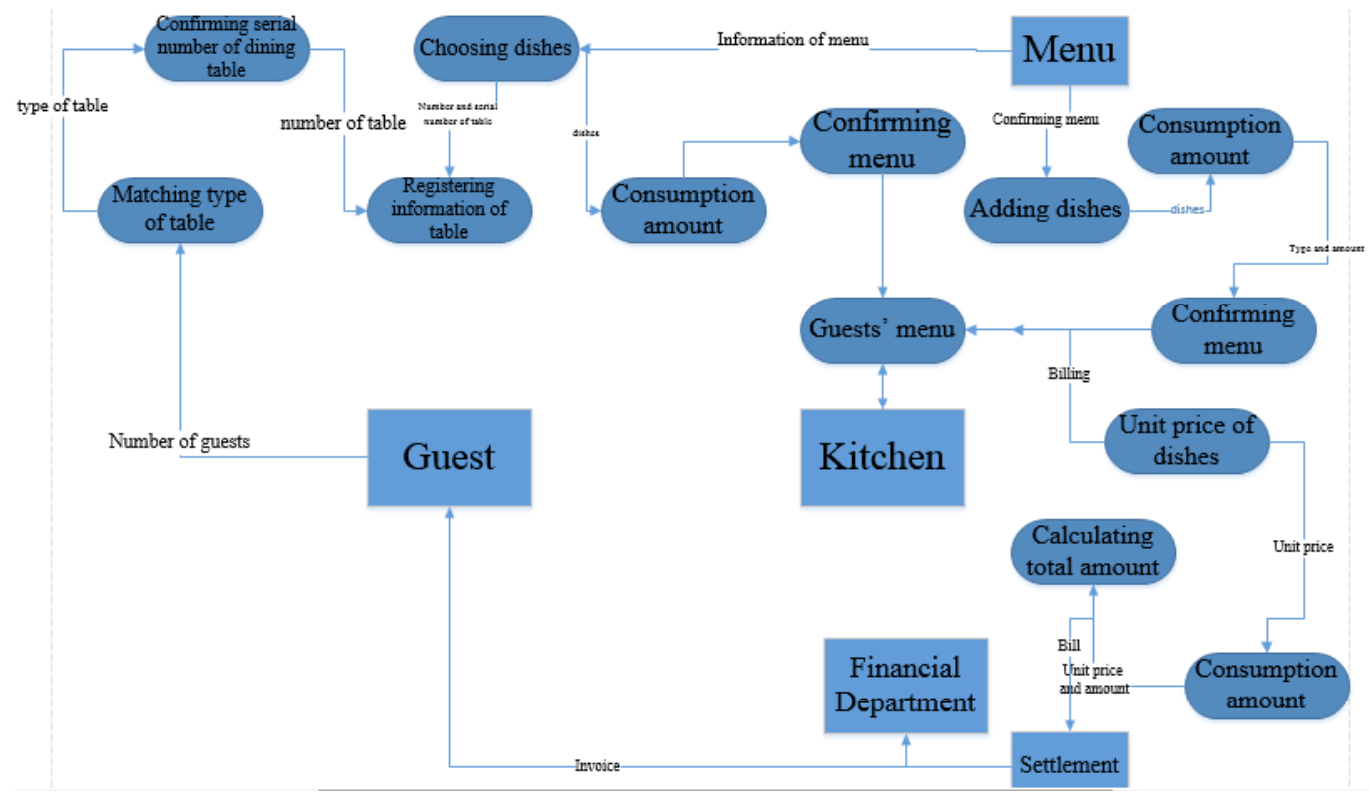

Fig. (4). Flow chart of third-class data of catering management system.

Bill (serial number of bill, total consumption amount and serial number of guests)

Kitchen (serial number and names of cooks)

Financial department (serial number and name of staffs, and reviewing date)

\subsubsection{Links Between Entities}

Guests' menu information — guests' dining table information: to order food time)

Guests' menu information - kitchen: to cook (cooking

Guests' menu information — bill: checkout (handler)

Financial department—bill: financial management (form filling date)

The specific E-R diagram is as Fig. (5).

\section{DATABASE LOGICAL DESIGN}

\subsection{Converting E-R Diagrams to Relation Table}

Relation schema can be divided into:

Guests (serial number of guests, number of guests, serial number of dining table, serial number of dishes and consumption amount)

Menu (serial number of dishes, and names, price and details of dishes)

Dining table (serial number of dining table, location, status and type of dining table)

Bill (serial number of bill, total consumption amount, serial number of guests and handler)

Kitchen (serial number of cooks, name of cooks and cooking time) 


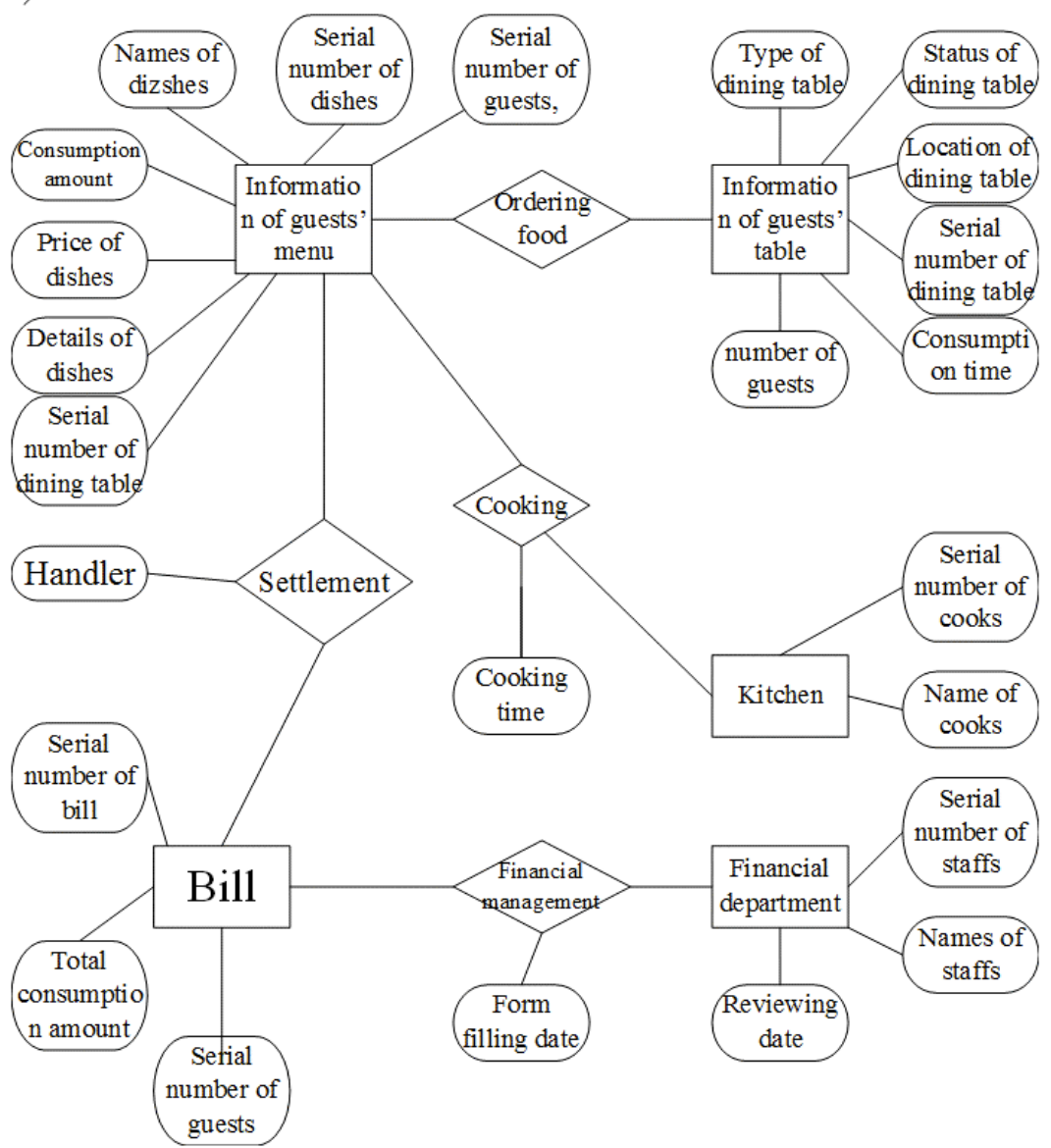

Fig. (5). E-R diagram of catering management system.

Financial department (serial number of staffs, names of staffs, reviewing and form filling dates)

\subsection{Relational Descriptions of Basic Table}

Guests (serial number of guests, number of guests, serial number of dining table, serial number of dishes and consumption amount)

In this mode, there is no partial functional dependency or transitive functional dependency of any attributes to the primary code, "serial number of guests" [2]. Therefore, this mode is regarded as $3 \mathrm{NF}$. In the meantime, "serial number of guests" is the only primary code, so that this mode belongs to $\mathrm{BCNF}[3]$.

Menu (serial number of dishes, and names, and price of dishes) [4].

In this mode, there is no partial functional dependency or transitive functional dependency of any attributes to the primary code, "serial number of dishes". Therefore, this mode is regarded as $3 \mathrm{NF}$. In the meantime, "serial number of dishes" is the only primary code, so that this mode belongs to $\mathrm{BCNF}$.

Dining table (serial number of dining table, location, status and type of dining table) [5].

In this mode, there is no partial functional dependency or transitive functional dependency of any attributes to the pri- mary code, "serial number of dining table". Therefore, this mode is regarded as $3 \mathrm{NF}$. In the meantime, "serial number of dining table" is the only primary code, so that this mode belongs to BCNF.

Bill (serial number of bill, total consumption amount, serial number of guests and handler) [6].

In this mode, there is no partial functional dependency or transitive functional dependency of any attributes to the primary code, "serial number of bill". Therefore, this mode is regarded as $3 \mathrm{NF}$. In the meantime, "serial number of bill" is the only primary code, so that this mode belongs to BCNF.

Kitchen (serial number of cooks, name of cooks and cooking time)

In this mode, there is no partial functional dependency or transitive functional dependency of any attributes to the primary code, "serial number of cooks". Therefore, this mode is regarded as $3 \mathrm{NF}$. In the meantime, "serial number of cooks" is the only primary code, so that this mode belongs to BCNF.

Financial department (serial number of staffs, names of staffs, reviewing and form filling dates)

In this mode, there is no partial functional dependency or transitive functional dependency of any attributes to the primary code, "serial number of staffs". Therefore, this mode is regarded as $3 \mathrm{NF}$. In the meantime, "serial number of staffs" is the only primary code, so that this mode belongs to BCNF. 
3.3. Definition View and Index, Primary Key Words and Definition Authority

\subsubsection{Definition View}

(1) Code preview of view kitchen list if exists (select 1 from sysobjects where id = object_id('KitchenList') and type $=$ ' $\mathrm{V}$ ')

drop view KitchenList go

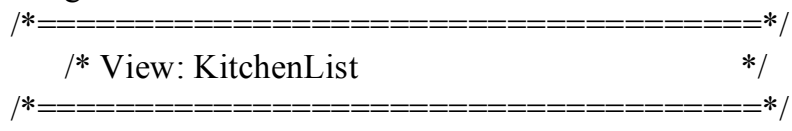

create view KitchenList as

select names of cooks and cooking time from kitchen

go

(2) Code preview of view food list

if exists (select 1 from sysobjects where id = object_id('FoodList') and type $=$ 'V')

drop view FoodList go

\begin{tabular}{|c|c|}
\hline /* View: FoodList & $* /$ \\
\hline
\end{tabular}

create view FoodList as

select names of dishes, price of dishes, details of dishes

from menu

go

(3) Code preview of view financial department list if exists (select 1 from sysobjects where id = object_id('FinanceDepartmenList') and type $=$ ' $\mathrm{V}$ ')

drop view FinanceDepartmenList go

\begin{tabular}{|c|c|c|}
\hline$* /{ }^{1 *}$ & View: & FinanceDepartmenList \\
\hline
\end{tabular}

create view FinanceDepartmenList as

select names of staffs, reviewing date, form filling date

from financial department go

(4) Code preview of view bill list

if exists (select 1

from sysobjects

where id $=$ object_id('BillList')

and type $=$ ' $\mathrm{V}$ ')

drop view BillList

go

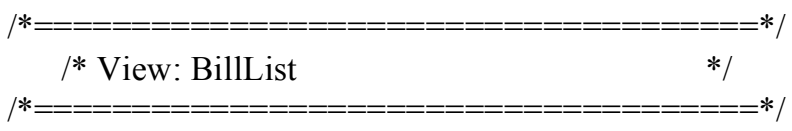

create view BillList as

select total consumption amount, serial number of guests, handler

from bill

go

(5) Code preview of view guest list

if exists (select 1

from sysobjects

where id = object_id('GuestList')

and type $=$ ' $\mathrm{V}$ ')

drop view GuestList

go

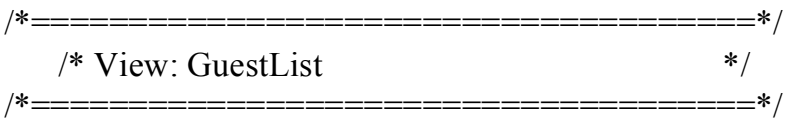

create view GuestList as

select serial number of guests, serial number of dining table, serial number of dishes, consumption amount

from guests

go

(6) Code preview of view table list

if exists (select 1

from sysobjects

where id = object_id('TableList')

and type $=$ ' $\mathrm{V}$ ')

drop view TableList

go

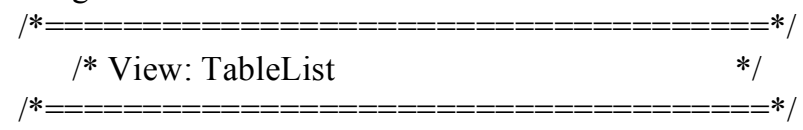

create view TableList as

select serial number of dining table, status of dining table

from dining table

go

\subsubsection{Definition Index}

(1) Code preview of index of tabular kitchen

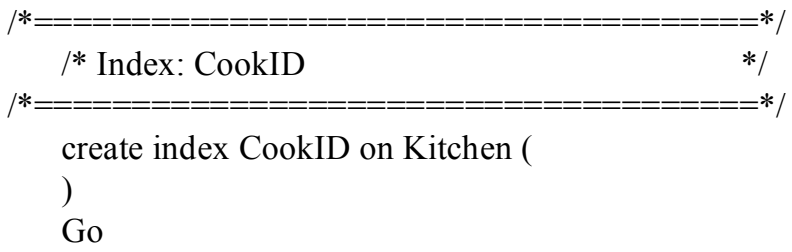

(2) TABCode preview of index of tabular menu

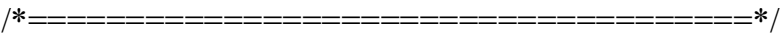

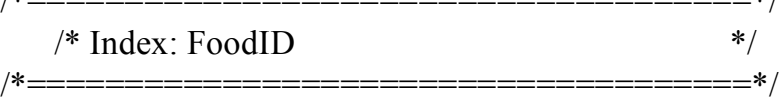

create index FoodID on Food (

)

Go

(3) Code preview of index of tabular financial department 


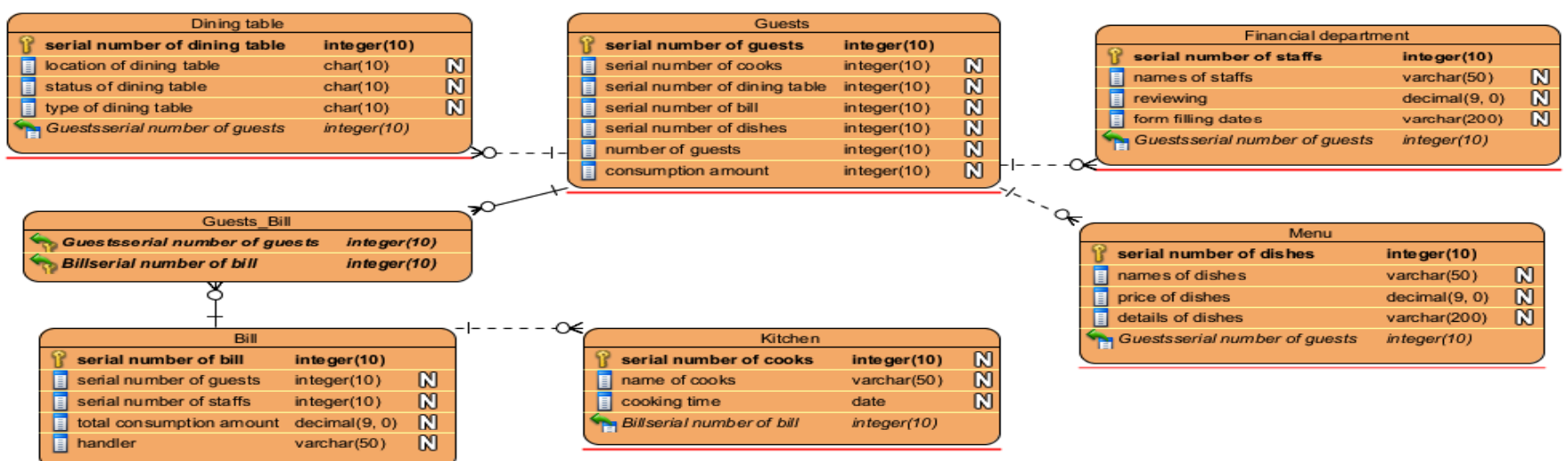

\begin{tabular}{|l|}
\hline \multicolumn{1}{|c|}{ Fina ncial de partment list } \\
\hline -names of staffs \\
-reviewing \\
-form filling date \\
\hline +Financial department() \\
\hline
\end{tabular}

\section{Dining table list} -serial number of dining table -status of dining table +Dining table 0

\begin{tabular}{|l|}
\hline \multicolumn{1}{|c|}{ Gues ts list } \\
\hline -serial number of guests \\
-serial number of dining table \\
-serial number of dishes \\
-consumption amount \\
\hline +Guests() \\
\hline
\end{tabular}

Fig. (6). Observation plans for the annual and quinquennial samples.

(4) Code preview of index of tabular bill

$/ *=============================* /$
$/ *$ Index: BilliD
$/ *=================================* /$

create index BillID on Bill (

)

Go

(5) Code preview of index of tabular guest

$/ *=============================* /$

/* Index: GuestID */

$/ *================================* /$

create index GuestID on Guest (

)

Go

(6) TABCode preview of index of tabular dining table

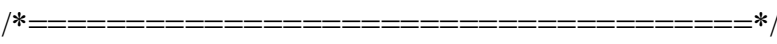

/* Index: TableID

$* /$

$/ *===============================*$ /

create index TableID on Table (

)
}

Go

\subsubsection{KEY WORD Primary Key Words}

Guest: serial number of guests

Menu: serial number of dishes

Dining table: serial number of dining table

Bill: serial number of bill

Kitchen: serial number of cooks Financial department: serial number of staffs

\section{DATABASE LOGICAL DESIGN}

The design shows from Tables 1-10. Physical model of database of catering management system is as Fig. (6).

Table 1. Table list of catering management system.

\begin{tabular}{|c|c|}
\hline Name & Code \\
\hline \hline Kitchen & Kitchen \\
\hline Menu & Food \\
\hline Financial Department & FnanceDepartment \\
\hline Bill & Bill \\
\hline Guest & Guest \\
\hline Dining Table & Table \\
\hline
\end{tabular}


Table 2. Table column list of catering management system.

Table 2. Contd......

\begin{tabular}{|c|c|}
\hline Name & Code \\
\hline Serial number of guest & GuestID \\
\hline Serial number of cook & CookID \\
\hline Serial number of dining table & TableID \\
\hline Serial number of bill & BillID \\
\hline Serial number of dishes & FoodID \\
\hline Number of guests & GuestNum \\
\hline Consumption amount & FoodSum \\
\hline Serial number of dishes & FoodID \\
\hline Name of dishes & FoodName \\
\hline Price of dishes & FoodPrice \\
\hline Details of dishes & FoodDescription \\
\hline Serial number of dining table & TableID \\
\hline Location of dining table & TableLocation \\
\hline Status of dining table & TableStatus \\
\hline Type of dining table & TableType \\
\hline Serial number of bill & BillID \\
\hline Serial number of guest & GuestID \\
\hline Serial number of staff & WorkerID \\
\hline
\end{tabular}

\begin{tabular}{|c|c|}
\hline Name & FoodAllPrice Code \\
\hline \hline Total consumption amount & \\
\hline Handler & PersonHanding \\
\hline Serial number of cook & CookID \\
\hline Name of cook & CookName \\
\hline Cooking time & CookingTime \\
\hline Serial number of staff & WorkerID \\
\hline Name of staff & WorkerName \\
\hline Reviewing date & ReviewDate \\
\hline Form filling date & FillingDate \\
\hline
\end{tabular}

Table 3. Table key list of catering management system.

\begin{tabular}{|c|c|c|}
\hline Name & Code & Table \\
\hline \hline Identifier_1 & Identifier_1 & Guest \\
\hline Identifier_1 & Identifier_1 & Menu \\
\hline Identifier_1 & Identifier_1 & Dining table \\
\hline Identifier_1 & Identifier_1 & Bill \\
\hline Identifier_1 & Identifier_1 & Kitchen \\
\hline Identifier_1 & Identifier_1 & Financial department \\
\hline
\end{tabular}

Table 4. Table index list of catering management system.

\begin{tabular}{|c|c|c|c|c|c|c|c|}
\hline Name & Code & Only & Clusters & Primary & External Key & Candidate Key & Table \\
\hline Guest_PK & Guest_PK & TRUE & FALSE & TRUE & FALSE & FALSE & Guest \\
\hline Use_FK & Use_FK & FALSE & FALSE & FALSE & TRUE & FALSE & Guest \\
\hline $\begin{array}{l}\text { SettleAc- } \\
\text { counts_FK }\end{array}$ & $\begin{array}{l}\text { SettleAc- } \\
\text { counts_FK }\end{array}$ & FALSE & FALSE & FALSE & TRUE & FALSE & Guest \\
\hline Order_FK & Order_FK & FALSE & FALSE & FALSE & TRUE & FALSE & Guest \\
\hline Cooking_FK & Cooking_FK & FALSE & FALSE & FALSE & TRUE & FALSE & Guest \\
\hline Food_PK & Food_PK & TRUE & FALSE & TRUE & FALSE & FALSE & Menu \\
\hline Table_PK & Table_PK & TRUE & FALSE & TRUE & FALSE & FALSE & Dining table \\
\hline Bill_PK & Bill_PK & TRUE & FALSE & TRUE & FALSE & FALSE & Bill \\
\hline $\begin{array}{l}\text { SettleAc- } \\
\text { counts2_FK }\end{array}$ & $\begin{array}{l}\text { SettleAc- } \\
\text { counts2_FK }\end{array}$ & FALSE & FALSE & FALSE & TRUE & FALSE & Bill \\
\hline $\begin{array}{c}\text { FinanceMan- } \\
\text { age_FK }\end{array}$ & $\begin{array}{c}\text { FinanceMan- } \\
\text { age_FK }\end{array}$ & FALSE & FALSE & FALSE & TRUE & FALSE & Bill \\
\hline Kitchen_PK & Kitchen_PK & TRUE & FALSE & TRUE & FALSE & FALSE & Kitchen \\
\hline $\begin{array}{c}\text { FnanceDepart- } \\
\text { ment PK }\end{array}$ & $\begin{array}{c}\text { FnanceDepart- } \\
\text { ment PK }\end{array}$ & TRUE & FALSE & TRUE & FALSE & FALSE & $\begin{array}{c}\text { Financial de- } \\
\text { partment }\end{array}$ \\
\hline
\end{tabular}


Table 5. List of table kitchen of catering management system.

\begin{tabular}{|c|c|}
\hline Name & Code \\
\hline \hline Serial number of cooks & CookID \\
\hline Name of cooks & CookName \\
\hline Cooking time & CookingTime \\
\hline
\end{tabular}

Table 6. List of table menu of catering management system.

\begin{tabular}{|c|c|}
\hline Name & Code \\
\hline \hline Serial number of dishes & FoodID \\
\hline Name & Code \\
\hline Name of dishes & FoodName \\
\hline Price of dishes & FoodPrice \\
\hline Details of dishes & FoodDescription \\
\hline
\end{tabular}

Table 7. List of table financial department of catering management system.

\begin{tabular}{|c|c|}
\hline Name & Code \\
\hline \hline Serial number of staffs & WorkerID \\
\hline Name of staffs & WorkerName \\
\hline Reviewing date & ReviewDate \\
\hline Form filling date & FillingDate \\
\hline
\end{tabular}

Table 8. List of table bill of catering management system.

\begin{tabular}{|c|c|}
\hline Name & Code \\
\hline \hline Serial number of bill & BillID \\
\hline Serial number of guest & GuestID \\
\hline Serial number of staff & WorkerID \\
\hline Total consumption amount & FoodAllPrice \\
\hline Handler & PersonHanding \\
\hline
\end{tabular}

\section{CONCLUSION}

According to actual users' requirements, this paper conducts analysis and design, seeks the inter relation, construct the concept of database and the relative logical mode and physical structure, and create database based on the previous to storage and manage data effectively. Through research on relation database, this paper constructs a modern and efficient management system. By constructing logical and physical design of database, this paper creates a high-
Table 9. List of table guest of catering management system.

\begin{tabular}{|c|c|}
\hline Name & Code \\
\hline \hline Serial number of guest & GuestID \\
\hline Serial number of cook & CookID \\
\hline Serial number of dining table & TableID \\
\hline Serial number of bill & BillID \\
\hline Serial number of dishes & FoodID \\
\hline Number of guests & GuestNum \\
\hline Consumption amount & FoodSum \\
\hline
\end{tabular}

Table 10. List of table dining table of catering management system.

\begin{tabular}{|c|c|}
\hline Name & Code \\
\hline \hline Serial number of dining table & TableID \\
\hline Location of dining table & TableLocation \\
\hline Status of dining table & TableStatus \\
\hline Type of dining table & TableType \\
\hline
\end{tabular}

efficiency information system of multimedia catering management.

\section{CONFLICT OF INTEREST}

The author confirms that this article content has no conflict of interest.

\section{ACKNOWLEDGEMENTS}

This work is supported by the Key Project of Guangxi Social Sciences, China (No. gxsk201424), the Education Science fund of the Education Department of Guangxi, China (No. 2014JGA268), and Guangxi Office for Education Sciences Planning, China (No. 2013C108).

\section{REFERENCES}

[1] L. Zhou, J. Wang, and M. Xu, Design and Practice of Database Application System, Beijing: China Railway Publishing House, pp. 149-155, 2010.

[2] Y. Fan, J. Zeng, S. Zhao, and Z. Wu, "Practical graphical management mechanism of mining rights based on relation database", Land and Resources Informatization, vol. 2, pp. 20-22,34, 2003.

[3] P. Zong, and J. Qin, "Research and realization of active information system based on relation database", Computer Engineering and Applications, vol. 14, pp. 93-95, 2001.

[4] H. Zhao, Y. Jiang, M. Jiang, S. Han, "Design and realization of spatial database of deployment and management system of water resources in heihe river basin", Water Resources and Hydropower Engineering, vol. 4, pp. 1-4, 2004. 
[5] X. Deng, and W. Wang, "Research on organizational management and application of spatial data based on relation database, Microcomputer Applications, vol. 12, pp. 53-54, 2009.
[6] X. Huang, H. Bi, "Research on pattern and operation of relation database and object database" Journal of Chinese Computer Systems, vol. 11, pp. 62-69, 1997.

Received: June 10, 2015

Revised: July 29, 2015

Accepted: August 15, 2015

(C) Lin Xie; Licensee Bentham Open.

This is an open access article licensed under the terms of the (https:/creativecommons.org/licenses/by/4.0/legalcode), which permits unrestricted, noncommercial use, distribution and reproduction in any medium, provided the work is properly cited. 